\title{
Threatened fishes of the world: Cyprinus ilishaestomus (Chen \& Hwang, 1977) (cyprinidae)
}

\author{
GuangFu Hu $\cdot$ XiangJiang Liu
}

Received: 6 May 2008 / Accepted: 22 September 2008 / Published online: 3 October 2008

(C) Springer Science + Business Media B.V. 2008

Common name: Top-mouth carp (English), Longyan carp (Chinese). Conservation status: Critically endangered, Class II protected animal of Yunnan Province (Yue and Chen 1998). Identification: D.IV, 16-17; A. III, 5; P.I, 16-17; V.I, 8-9. Gill rakers: upper 20-22, lower 28-29 (Chu and Chen 1989). Body typically carp-like, mouth is superior, no barbels, body covered with large scales, eyes are large. Yellowish green dorsum, the abdominal region is silvery white (Yue and Chen 1998). Drawing by Wu XW (Wu 1982). Distribution: C. ilishaestomus is restricted to the Qilu Lake of Yunnan Province, China (Wang 1979). Abundance: Formerly an economically important fish, but its numbers dropped sharply since the 1970s and now it is almost extinct. Habitat and ecology: Dwells mainly in deep water. It is an omnivore, feeds on shrimps, small fishes and some aquatic plants. Threats: Habitat degradation is the critical threat, including water pollution and reduction of the lake area. Introduced grass carp, Ctenopharyngodon idella, grazed macrophytes heavily and reduced habitat and food of C. ilishaestomus. Overfishing also

G. $\mathrm{Hu}(\bowtie) \cdot X$. Liu

College of Fishery, Huazhong Agricultural University,

Wuhan, Hubei, China 430070

e-mail: huguangfu@126.com

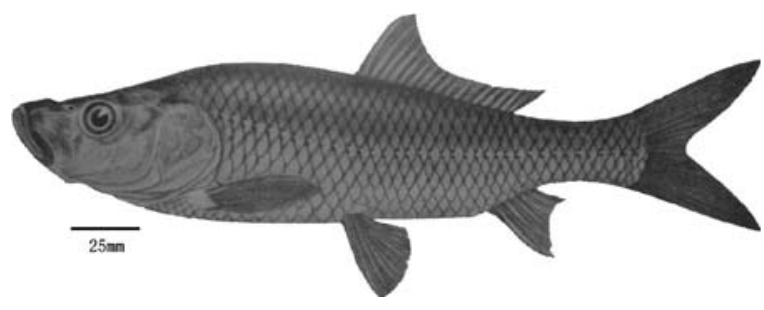

remains a threat to the species. Conservation action: No specific action has been adopted. Conservation recommendation: First, protect the ecological environment for the Top-mouth carp in Qilu Lake. In addition, biological research on population ecology, habitat requirements and reproduction are required.

\section{References}

Chu XL, Chen YR (1989) The fishes of Yunnan, China Part I Cyprinidae. Science, Beijing, China, pp 348-349

Wang YH (1979) On the classification, distribution, origin and evolution of the fishes referred to the subfamily cyprininae of China, with description of a new species. Acta Hydrobiol Sin 6(4):420-434

Wu XW (1982) China cyprinid fishes record Part II. Shanghai Science and Technology, Shanghai, China, pp 427-428

Yue PQ, Chen YY (1998) China Red Data Book of endangered animals-Pisces. Science, Beijing, Hong Kong, New York, pp 189-190 